\title{
SOCIOLINGUÍSTICA NA SALA DE AULA: RELAÇÕES COM O ENSINOIAPRENDIZAGEM DE LÍNGUA MATERNA
}

Thábata Christina Gomes de Lima

RESUMO

A Sociolinguística trouxe consigo a importância de concebermos as línguas como heterogêneas, como atividades sociais, e de percebermos que a variação é um fenômeno inerente a elas. Com isso, novas concepçôes teóricas e metodológicas relacionadas ao processo de ensino-aprendizagem de língua materna começaram a surgir. Neste artigo, refletiremos sobre como esta corrente teórica pode influenciar nas práticas docentes.

PALAVRAS-CHAVE: sociolinguística; língua materna; ensino-aprendizagem.

\section{Introdução}

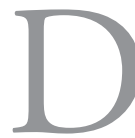

e acordo com Bagno (2011, p. 355), “o conceito de língua não é o mais fácil de se definir”. Dependendo da perspectiva adotada, podemos percorrer por diversas correntes teóricas, cada qual delimitando o seu objeto de pesquisa, que pode ser o texto, a enunciação, a língua em uso, entre outros.

Antes mesmo do "surgimento" da Linguística, com Ferdinand de Saussure, as questóes referentes ao ensino/aprendizagem de língua materna são debatidas. Saussure, ao postular que toda língua comporta uma estrutura, abriu caminho para que todas as línguas fossem vistas como fenômenos analisáveis, independentes de que gozassem ou náo de prestígio pela comunidade de fala. Assim: 
Apontando como objetivo primordial a depreensão da estrutura das línguas, o estruturalismo criou a convicção de que as línguas mal documentadas - por exemplo as línguas ágrafas, ou as variantes não padrão das línguas de cultura - constituíam um objeto de reflexão tão legítimo como as grandes línguas que os europeus vinham estudando havia séculos (ILARI, 2011, p. 66).

Desta forma, com o Estruturalismo começou-se a estudar as línguas e a buscar depreender a sua estrutura. Para Ilari (2011), através desta corrente teórica, a língua portuguesa, tal como é falada e escrita no Brasil, passou a ser tomada como objeto de descrição, buscando-se, com isso, valorizar alguns aspectos da nossa realidade linguística, como as variedades regionais, por exemplo. Porém:

A grande contribuição que o estruturalismo deixou no ensino refere-se à pedagogia da língua materna e consistiu, antes de mais nada, em mostrar a precariedade da doutrina gramatical que vinha sendo tradicionalmente ensinada pela escola: hoje, qualquer pessoa medianamente informada sabe que essa doutrina recomenda uma linguagem que não é nem a do povo, nem a dos grandes veículos de comunicação, nem a dos escritores (ILARI, 2011, p. 89).

Apesar de reconhecer que a língua ensinada nas escolas diferenciava-se da realidade das pessoas, o estruturalismo náo levava em conta que a variaçáo era um fenômeno inerente às línguas. E, ao valorizar a língua, em detrimento da fala, os aspectos sociais foram descartados, pois no estudo imanente da língua "toda preocupação extralinguística precisa ser abandonada, uma vez que a estrutura da língua deve ser descrita apenas a partir de suas relaçôes internas" (COSTA, 2011, p. 115).

De acordo com Cezario e Votre (2011, p. 146), "como fruto da insatisfação diante dos modelos existentes que afastavam o objeto da realização da língua e de suas diversas manifestaçóes, vários linguistas procuraram outros caminhos". E um deles resultou no surgimento de uma corrente teórica conhecida como Sociolinguística. 


\section{A Sociolinguística e o fenômeno da variação}

Cezario e Votre (2011) nos dizem que o termo "sociolinguística" surge pela primeira vez na década de 1950. Nos Estados Unidos, desenvolveu-se como corrente na década de 1960, especialmente com os trabalhos realizados por diversos linguistas, como Labov, Gumperz e Hymes.

De acordo com Reis, Machado e Barbosa (2011, p. 6442):

A sociolinguística é uma área de estudo e investigação do fenômeno linguístico em seu contexto social e cultural, em situaçóes reais de uso dentro da comunidade linguística. A teoria sociolinguística surge em meados da década de 60 como uma espécie de reação às teorias estruturalista e gerativista transformacional, uma vez que veio propor a consolidaçáo de uma concepção de linguagem essencialmente social, correlacionando sistematicamente a língua à história social dos falantes e considerando como ponto inicial de análise a diversidade própria de uma comunidade linguística.

Esta corrente teórica vem propor uma nova visão para os fatos linguísticos. A variação é vista como constitutiva das línguas. A diversidade não é tomada como um problema, mas como algo a ser observado, descrito e analisado.

A Sociolinguística busca estudar a língua em seu uso real, ou seja, em situações reais de comunicação. Os aspectos externos são considerados fundamentais para uma análise linguística efetiva. A língua é considerada "uma instituição social e, portanto, não pode ser estudada como uma estrutura autônoma, independente do contexto situacional, da cultura e da história das pessoas que a utilizam como meio de comunicação" (CEZARIO, VOTRE, 2011, p. 141).

Assim, o aspecto social é dotado de um valor muito grande. E a fala, menosprezada pelos estruturalistas, passa a ter um papel fundamental nestes estudos. Começam a surgir análises de falantes em situações diversas, levando-se em conta o contexto em que ocorre a comunicaçáo, que precisa ser com falantes/ouvintes reais e não mais idealizados. 
Dentro da Sociolinguística surgiram várias vertentes, como a Sociolinguística Interacional, a Sociolinguística de Contatos (mais conhecida como Sociologia da Linguagem) e a Sociolinguística Variacionista, entre outras.

De um modo geral, a mais difundida foi a Sociolinguística Variacionista, também chamada de "Teoria da Variação" ou "Teoria Laboviana". Tendo como um de seus principais precursores o linguista americano William Labov, esta abordagem "baseia-se em pressupostos teóricos que permitem ver regularidade e sistematicidade por trás do aparente caos da comunicação do dia a dia” (CEZARIO, VOTRE, 2011, p. 142).

Por trabalhar com uma grande quantidade de dados e utilizar sistemas computacionais e outros métodos para quantificá-los, esta vertente não é considerada, por muitos estudiosos, como uma teoria. É vista, geralmente, como um método para analisar um grande número de dados. Porém esta é uma questão irrelevante neste momento.

Partindo do pressuposto de que a Sociolinguística Variacionista é uma corrente teórica, analisaremos algumas de suas principais características.

\section{A vertente variacionista}

De acordo com Camacho (2001, p. 50):

Nesse enfoque, o exame da linguagem no contexto social é tão importante para a solução de problemas próprios da teoria da linguagem, que a relação entre língua e sociedade é encarada como indispensável, não mero recurso interdisciplinar. Como a linguagem é, em última análise, um fenômeno social, fica claro, para um sociolinguista, que é necessário recorrer às variaçôes derivadas do contexto social para encontrar respostas para os problemas que emergem da variação inerente ao sistema linguístico.

Assim, ao contrário das correntes formalistas, a Sociolinguística considera extremamente importante a observação dos fatos extralinguísticos. O contexto social e tudo o que se refere ao indivíduo (idade, sexo/gênero, escolaridade, grau de formalidade da situação) é levado em consideração na hora da análise linguística. 
Outro ponto fundamental, especialmente para essa vertente teórica, encontra-se na questão da variação:

Se as línguas naturais humanas consistem em sistemas organizados de forma e conteúdo, seria estranho que a variação náo fosse uma de suas propriedades mais marcantes e significativas. $\mathrm{Na}$ realidade, a diversidade é uma propriedade funcional e inerente aos sistemas linguísticos e o papel da Sociolinguística é exatamente enfocá-la como objeto de estudo, em suas determinaçóes linguísticas e não linguísticas (CAMACHO, 2001, p. 55).

Desta maneira, o que esta corrente propóe é uma análise do que outrora não fora considerado, ou em outros casos, visto com menosprezo. A Sociolinguística vem propor uma nova visão: a de que não há erro na língua e sim, variação. A língua é tida como um sistema heterogêneo e variável. E o prestígio ou não de uma determinada variante ${ }^{1}$ é concebido levando-se em conta outros aspectos, em geral, inerentes ao sistema linguístico, tais como status e autoridade de quem a emprega. Para Camacho (2001, p. 59):

As formas em variação adquirem valores em função do poder e da autoridade que os falantes detêm nas relaçóes econômicas e culturais. [...] O mecanismo é simples: como os detentores da variedade ${ }^{2}$ de prestígio controlam o poder político das instituiçôes, que emana das relaçôes econômicas e sociais, são também detentores da autoridade de vincular a língua à variedade que empregam.

Com isso, começaram a surgir debates em relação ao prestígio/estigma de determinadas variedades. Os novos estudos vieram mostrar que as mais prestigiadas eram, de fato, as menos faladas pela comunidade de fala. As con-

1 O termo variante é utilizado, segundo Cezario e Votre (2011, p. 142), para “identificar uma forma que é usada ao lado de outra na língua, sem que se verifique mudança no significado básico”.

2 As variedades linguísticas são consideradas como os diversos modos de falar (ALKMIM, 2001, p. 32). 
sideradas "padrão" eram, em geral, dominadas por uma pequena parcela da população: a que gozava de um melhor status econômico e político.

Desta maneira, percebeu-se que o valor de uma variante era medido mais em termos sociais do que propriamente linguísticos. E a consequência que esta abordagem trazia para os falantes começou a ser estudada e questionada, pois:

A natureza discriminatória que a linguagem pode assumir, em função da variação linguística e dos mecanismos de estigmatização, leva-nos, professores e pesquisadores, a refletir sobre a questâo que mais nos afeta: em que grau o processo de ensino da língua materna contribui para o agravamento ou para a simples manutenção das situações de exclusão [...] a que está sujeita a população socialmente marginalizada? (CAMACHO, 2001, p. 67)

A Sociolinguística, portanto, trouxe uma nova perspectiva para o ensino das variedades linguísticas. De acordo com Silva (2009, p. 29), é importante ressaltar que

[...] não existe nada inerente a uma variante que a defina como "bom", "ruim", "correto", ou "incorreto". A sociolinguística é uma ciência, não uma filosofia ou ideologia - todos os dialetos são "corretos". Cada um deles tem sua gramática, sua lógica, sua pertinência, sua adequação social. Não há um "padrão correto" do ponto de vista científico, porque esse "padrão" é o dos grupos dominantes.

Antes, porém, de discutirmos sobre este assunto, torna-se necessário refletir sobre como as questóes referentes ao conceito de língua e variação que, em geral, vigoram nas práticas docentes, podem contribuir para a estigmatização dos alunos e, consequentemente, para a evasão escolar.

\section{Uma "norma" excludente}

Como vimos, o Estruturalismo trouxe a reflexão sobre as diferentes "normas" que se apresentavam na língua: uma, ensinada nas escolas, mas desco- 
nhecida, na prática, por seus falantes, e outra, excluída pela escola, mas utilizada pela maioria da população.

Apesar disso, nesta corrente teórica não há um "modelo" de base para o ensino de língua em sala de aula. Então, por muito tempo, prevaleceu a seguinte dúvida: Que modelo ensinar?

De acordo com Perfeito (2007, p. 827), a linguagem, nesta concepção de ensino, "[...] é entendida como código. E o estudo da língua, apesar de propostas de inovaçóes, ainda tende ao ensino gramatical, embora a leitura e a produção textual comecem a ganhar maior relevância na escola, ao lado dos elementos da teoria da comunicação".

Seguindo os métodos estruturalistas, o que "deve" ser priorizado no ensino/aprendizagem de língua materna são as regras gramaticais. Mesmo postulando que nenhum sistema linguístico é considerado "melhor" ou "pior" que outro, há uma preocupação em "seguir as normas". A língua é vista aqui como um sistema homogêneo, já que a variação linguística é tomada como "erro", ou no mínimo, como um desvio. E, por isso, há a necessidade de um enfoque nos aspectos intralinguísticos.

Perfeito (2007, p. 827) afirma que:

Em termos gramaticais, sem o abandono, na prática, do ensino da gramática tradicional, a concepção de linguagem como forma de comunicação focaliza o estudo dos fatos linguísticos por intermédio de exercícios estruturais morfossintáticos, na busca da internalização inconsciente de hábitos linguísticos, próprios da norma culta. Isto é relevado, por exemplo, em livros didáticos ou em apostilas, que apresentem exercícios mecânicos tais como: atividades de seguir modelo(s), de múltipla escolha e/ou completar lacunas.

Podemos perceber que esta concepção de linguagem está focada em "apreender" a "norma" culta, vista em muitos casos, como uma "norma padrão". Mas, o que vem a ser esta "norma” padrão e quais as consequências desta incessante busca para o processo de ensino/aprendizagem de português como língua materna? 


\section{A concepção de "norma" e as consequências de uma "padronização"}

Segundo Faraco (2011, p. 259):

O conceito de norma foi criado basicamente para dar conta da variação linguística, ou seja, para acomodar no modelo saussuriano de língua e fala uma terceira camada teórica capaz de captar a diversidade intralinguística, sem abandonar a ideia da existência de um grande sistema que autoriza os diferentes usos coletivos, ou seja, os usos normais das diversas comunidades que, não obstante as diferenças, se identificam como falantes de uma mesma língua.

Este conceito foi introduzido pelo linguista romeno Eugenio Coseriu, ao estabelecer uma instância intermediária entre o sistema língua-fala, proposto por Saussure, a qual deveria abranger a parte social da linguagem. Estaria, de certa forma, relacionado a um sistema regulador dos usos linguísticos na comunidade de fala.

Mas, ao longo dos anos, este vocábulo esteve, praticamente, indissociável ao conceito de "norma-padrão". Para Milroy (2011, p. 57), "um efeito extremamente importante da padronização tem sido o desenvolvimento da consciência, entre os falantes, de uma forma de língua 'correta' ou canônica". Assim, a ideia de padronização afeta aos falantes, que começam a exibir julgamentos de valor em relação à "língua" que utilizam. E, com este conceito, surgem atitudes em face ao prestígio ou não que uma determinada variedade pode assumir. Aparecem discursos como "falar assim é certo" ou "deste modo é errado". Com isso, automaticamente, os falantes passam a julgados mediante a sua forma de falar.

Bagno (2011, p. 359) afirma que:

A criação de uma norma, de um parâmetro, de um modelo de língua ideal tem sido sempre um processo de "objetificação" da língua. Em seu estado "natural" [...], uma língua é sempre heterogênea, mutante, cambiante, variável, maleável e flexível. O processo de padronização agarra a língua e a retira de sua vida 
íntima, privada, comunitária, e a transforma numa instituição, num monumento cultural, em veículo de uma política nacional e, em várias ocasióes ao longo da história, de uma política imperial, colonial.

Desta maneira, ao passar por uma padronização, a língua transforma-se de um "organismo" flexível para algo "fechado", equiparado a um monumento. Deixa de ser uma língua materna e se torna uma língua paterna, a língua da pátria. O padrão linguístico é relacionado à língua do patrão (BAGNO, 2011, p. 359).

É a língua imposta, a língua que precisa ser constantemente polida, que não admite algo que seja diferente de suas regras. E, consequentemente, é uma língua idealizada, que acaba por desprestigiar aqueles que, porventura, divergem de seus "parâmetros".

Bagno (2011, p. 368) alerta para o fato de que há uma confusão entre a "norma-padrão" e a "norma-culta", a qual é considerada "o conjunto das variedades urbanas realmente empregadas pelas camadas privilegiadas da população”. Assim, confunde-se a variedade considerada culta pela comunidade de fala com um ideal linguístico, o qual, segundo Milroy (2011, p. 69), é "uma variedade que nunca é perfeitamente nem consistentemente realizada no uso falado".

Apesar de algumas correntes teóricas, como a Sociolinguística, terem aberto caminhos para uma nova visão de língua e, de certa forma, trazerem novas formas de abordar o fenômeno da variação linguística, em geral, o ensino privilegiado em muitas escolas brasileiras ainda está apegado à tradição estruturalista.

De acordo com Antunes (2013, p. 19):

Um exame mais cuidadoso de como o estudo da língua portuguesa acontece, desde o Ensino Fundamental, revela a persistência de uma prática pedagógica que, em muitos aspectos, ainda mantém a perspectiva reducionista do estudo da palavra e da frase descontextualizadas. Nesses limites, ficam reduzidos, naturalmente, os objetivos que uma compreensão mais relevante da linguagem poderia suscitar - linguagem que só funciona para que as pessoas possam interagir socialmente. 
Logo, em muitos momentos, o estudo da língua materna acaba por ficar reduzido ao estudo das palavras e das frases produzidas em situaçóes de fala artificiais. Desse modo,

A conclusão então é assustadora: o objetivo das aulas de língua na escola não é "ensinar português", mas simplesmente, e eu diria até obsessivamente, ensinar uma nomenclatura tradicional. Assim, em vez de ensinar/estudar um universo enorme e rico, que é a língua portuguesa, a escola se dedica quase exclusivamente a ensinar um pedacinho ínfimo e miserável desse universo (BAGNO, 2002, p. 50).

E isso acaba por refletir no processo de ensino/aprendizagem dos alunos, especialmente naqueles provenientes das camadas populares, já que:

É o uso da língua na escola que evidencia mais claramente as diferenças entre grupos sociais e que gera discriminaçóes e fracasso: o uso, pelos alunos provenientes das camadas populares, de variantes linguísticas social e escolarmente estigmatizadas provoca preconceitos linguísticos e leva a dificuldades de aprendizagem, já que a escola usa e quer ver usada a variante-padrão socialmente prestigiada (SOARES, 1987, p. 17).

Ao prestigiar a variante "padrão" e promover juízos de valor como "certo" ou "errado", a escola acaba por contribuir para o aumento do preconceito linguístico. O aluno, ao perceber que utiliza uma variedade linguística diferente da imposta pelo professor, tende a tomar para si os juízos atribuídos à língua e, consequentemente, a inibir-se em sala de aula. Prefere, na maioria das vezes, ficar calado a falar/escrever de uma forma considerada "ruim" ou "errada" pelos demais. A situação fica pior quando se torna alvo de críticas e de implicâncias de outros colegas.

Antunes (2012, p. 15-16) acrescenta que:

Infelizmente, os avanços conseguidos pelos estudos linguísticos ainda não chegaram ao grande público, nem mesmo àquele 
público que teve acesso ao estudo de língua na escola. Pelo contrário, o contato com esse estudo tem repercutido de forma pouco positiva nas pessoas, no que se refere às perspectivas com que veem a linguagem, a língua, a gramática, o vocabulário etc. Tudo se mistura numa imensa confusão, agravada pelas pressôes sociais em torno do ideal de um falar correto, supostamente mais perfeito e prova de superioridade intelectual e cognitiva. E o resultado é que, quando se sai da escola, se sai muito mais confuso, com uma visão de língua deturpada, reduzida e falseada, terreno muito propício à gestação de preconceitos e de simplismos incabíveis.

Assim, em muitos momentos, a escola acaba contribuindo para a propagação de certos estereótipos e preconceitos em torno de um suposto falar "correto". O aluno, por muitas vezes, tende a considerar as variedades linguísticas ensinadas e/ou privilegiadas na escola como melhores e/ou superiores.

Por isso:

Em vez de desejar o impossível, que seria ignorar os aspectos socioculturais e político-ideológicos, como tem feito o estruturalismo clássico e o gerativista, com seu "falante" ideal que não vive em nenhum lugar deste planeta, o mais sensato é buscar conhecer a dinâmica social da linguagem, seu impacto na vida das comunidades humanas, as origens culturais do próprio sistema linguístico, que não pode ser estudado fora das circunstâncias reais da vida de seus falantes (BAGNO, 2011, p. 363).

Desta forma, não basta apenas mostrar que há variação linguística, se não houver uma conscientização de que todas as variantes são estruturalmente significativas, e que, portanto, merecem respeito.

Logo:

Frente aos fenômenos da variação, não basta somente uma mudança de atitudes; a escola precisa cuidar para que não se reproduza em seu espaço a discriminaçâo linguística. Desse 
modo, não pode tratar as variedades linguísticas que mais se afastam dos padrôes estabelecidos pela gramática tradicional e das formas diferentes daquelas que se fixaram na escrita como se fossem desvios ou correçóes. [...] Por isso mesmo, o preconceito linguístico, como qualquer outro preconceito, resulta de avaliaçôes subjetivas dos grupos sociais e deve ser combatido com vigor e energia (BRASIL/SEF, 1998, p. 82).

A escola precisa trabalhar de modo a combater toda forma de discriminação e preconceito. E isto inclui os âmbitos linguísticos também. Não se pode aceitar um tratamento desrespeitoso em relação às variedades linguísticas, nem tratá-las como "peculiaridades".

Coan e Freitag (2010, p. 178) afirmam que é a partir da década de 1980 que as teorias linguísticas vêm auxiliar as escolas brasileiras no ensino de língua materna. Uma das principais correntes que buscaram uma mudança nesse processo de ensino/aprendizagem foi a Sociolinguística, a qual trouxe consigo a visão de heterogeneidade linguística, e com isso, a noção de que não há "erro" na língua.

É sobre a influência desta teoria e as consequências de uma "nova" concepção de língua e de variação no processo de ensino/aprendizagem de língua materna que trataremos a seguir.

\section{Novos caminhos para o ensino/aprendizagem de língua materna}

Não é nenhuma novidade que a língua ensinada nas escolas é, praticamente, uma língua irreal. Guedes (2006, p. 34) relata que, na aula de português, "o aluno fica sabendo que a língua que fala está errada e descobre que não é ali que vai aprender a usar uma língua certa, pois o que se aprende na aula de português só serve para a prova de português”. Assim, em muitos casos, os alunos não conseguem relacionar e/ou transpor os conteúdos apreendidos na escola para situaçóes reais e/ou cotidianas.

Durante muitos anos, várias correntes linguísticas tentaram desvencilhar-se dos paradigmas formalistas, buscando, entâo, um novo modo de estudar a língua materna em sala de aula. Apesar disso, ainda hoje, há muito o que se fazer. 
Segundo Antunes (2013, p. 19-20):

Embora muitas ações institucionais já se tenham desenvolvido, no sentido de motivar e fundamentar uma reorientação dessa prática, as experiências de renovação, infelizmente, ainda não ultrapassam o domínio das atividades assistemáticas, eventuais e isoladas.

Por isso, mesmo que um professor queira "inovar" e trabalhar a língua por um viés mais sociointeracional, geralmente, acaba por voltar-se a exercícios estruturais. Assim, torna-se difícil mudar a realidade de muitas escolas brasileiras. Note bem: difícil, mas não impossível.

É verdade que, em praticamente todos os âmbitos da sociedade, as pessoas são avaliadas mediante sua maneira de falar. Em uma entrevista de emprego, em uma apresentação acadêmica, entre outras situaçóes, exige-se o domínio da "norma-culta", que, como vimos, muitas vezes é confundida com a "norma-padrão", acarretando diversas consequências. Mas a escola, como instituição social, política e ideológica, precisa assumir um papel frente a estas circunstâncias. Logo, em pleno século XXI, são necessários os seguintes questionamentos: Como trabalhar a variação linguística de uma forma não preconceituosa? Como aceitar a variante utilizada pelo aluno se a sociedade privilegia a "variante-padrão"? É possível estabelecer uma relação entre a língua falada pelas camadas populares e a língua considerada, socialmente, de prestígio?

Soares (1987, p. 78) nos diz que:

Um ensino da língua materna comprometido com a luta contra as desigualdades sociais e econômicas reconhece, no quadro dessas relaçóes entre a escola e a sociedade, o direito que têm as camadas populares de apropriar-se do dialeto de prestígio, e fixa-se como objetivo levar os alunos pertencentes a essas camadas a dominá-lo, não para que se adaptem às exigências de uma sociedade que divide e discrimina, mas para que adquiram um instrumento fundamental para a participaçáo política e a luta contra as desigualdades sociais. 
Assim, a variante prestigiada pela sociedade deve ser entendida como uma forma a mais de um indivíduo expressar-se, e não como a única a ser aceita. O domínio da mesma deve ser visto como um instrumento na luta pelas desigualdades sociais, pois, como abordado anteriormente, "[...] a base do código normativo padrão é uma variedade linguística associada a usos e usuários privilegiados que, além disso, costuma ser adotada por este grupo de status como emblema distintivo de sua posição hegemônica" (MONTEAGUDO, 2011, p. 39). Tem mais relação com os aspectos sociais e econômicos do que com os linguísticos.

Com o advento da Sociolinguística, em especial, de sua vertente variacionista, novas tendências sobre estas questôes começaram a surgir. Um exemplo disso está presente nos Parâmetros Curriculares Nacionais (PCNs), que abordam a variação linguística da seguinte forma:

A variação é constitutiva das línguas humanas, ocorrendo em todos os níveis. Ela sempre existiu e sempre existirá, independentemente de qualquer postura normativa. [...] Embora no Brasil haja relativa unidade linguística e apenas uma língua nacional, notam-se diferenças de pronúncia, de emprego de palavras, de morfologia e de construçôes sintáticas, as quais não somente identificam os falantes de comunidades linguísticas em diferentes regióes, como ainda se multiplicam em uma mesma comunidade de fala. Não existem, portanto, variedades fixas: em um mesmo espaço social convivem mescladas diferentes variedades linguísticas, geralmente associadas a diferentes valores sociais. [...] O uso de uma ou outra forma de expressão depende, sobretudo, de fatores geográficos, socioeconômicos, de faixa etária, de gênero (sexo), da relação entre os falantes e do contexto de fala (BRASIL/SEF, 1998, p. 29).

Os PCNs, baseados nas premissas sociolinguísticas de que as línguas são sistemas heterogêneos e de que, portanto, têm a variação como algo constitutivo, falam da importância de se mostrar ao aluno que os usos de uma ou outra variante são determinados por diversos fatores. E que a escolha entre uma determinada forma de falar não está associada a ela ser "melhor" ou mais 
bonita, mas sim cultural e socialmente mais prestigiada.

Também alerta aos professores que:

No ensino-aprendizagem de diferentes padróes de fala e escrita o que se almeja náo é levar os alunos a falar certo, mas permitirlhes a escolha da forma de fala a utilizar, considerando os recursos expressivos, a variedade da língua e o estilo às diferentes situações comunicativas. [...] A questão não é de erro, mas de adequação às circunstâncias de uso, de utilização adequada da linguagem (BRASIL/SEF, 1998, p. 31).

O que se preconiza aqui é um ensino sem discriminação, em que os alunos possam perceber que, na verdade, não estão errados ao utilizarem uma variante estigmatizada pela comunidade de fala, mas sim inadequados. Que falar "a gente vamos", tem tanto valor estruturalmente do que "a gente vai/ nós vamos”. E, como citado anteriormente, apesar de os juízos de valor serem atribuídos às características culturais e/ou sociais, não tornam uma variante nem melhor nem pior que outra.

A importância destas reflexôes reside-se no fato de que:

O aluno é capaz de perceber que as formas da língua apresentam variação e que determinadas expressóes ou modos de dizer podem ser apropriados para certas circunstâncias, mas não para outras. Sabe, por exemplo, que existem formas mais ou menos delicadas de se dirigir a alguém, falas mais cuidadas e refletidas, falas cerimoniosas. Pode ser que saiba, inclusive, que certos falares são discriminados e, eventualmente, até ter vivido essa experiência (BRASIL/SEF, 1998, p. 81-82).

Assim, o aluno poderá perceber que não precisa deixar de lado a sua maneira de falar, mas que deve saber adequar-se ao contexto comunicativo. Que se ele quiser, pode continuar falando "pra mim fazer" com os amigos, mas que deverá dizer "para eu fazer" em situaçôes mais formais.

Não se trata de "obrigar" o aluno a mudar e/ou abandonar sua variante, mas de dar-lhe condiçôes de interagir nas mais diversas situaçôes sociocomu- 
nicativas. $\mathrm{O}$ problema da escola não está nos alunos utilizarem uma variante considerada inculta, mas em eles não conseguirem usar a "culta" quando necessário. Por isso:

Um ensino de língua materna que pretenda caminhar na direção desse objetivo tem de partir da compreensão das condiçôes sociais e econômicas que explicam o prestígio atribuído a uma variedade linguística em detrimento de outras, tem de levar o aluno a perceber o lugar que ocupa o seu dialeto na estrutura de relaçôes sociais, econômicas e linguísticas, e a compreender as razóes porque esse dialeto é socialmente estigmatizado; tem de apresentar as razóes para levar o aluno a aprender um dialeto que não é o do seu grupo social e propor-lhe um bidialetalismo não para sua adaptaçáo, mas para a transformação de suas condiçôes de marginalidade (SOARES, 1987, p. 78).

É necessário buscar os motivos que levam uma variante a ter um prestígio mais reconhecido que outro. $\mathrm{E}$ isso envolve questóes históricas, políticas e sociais. Além do que, é necessário refletir sobre o que leva um indivíduo a priorizar uma determinada forma de falar em detrimento de outras e sobre que perspectiva histórica, social e ideológica o falante está-se posicionando ao adotar uma variedade linguística.

Desta maneira, é necessário que a escola, principalmente na figura do professor, comece a refletir sobre os objetivos que pretende alcançar ao (re) produzir certas ideias e partilhar conhecimentos. É preciso pensar em que sujeitos pretende ajudar a formar: sujeitos críticos, que lutam por uma sociedade mais igualitária, ou sujeitos preconceituosos, reprodutores de práticas discriminatórias?

\section{Considerações finais}

Ao longo deste artigo, debatemos sobre as questóes relacionadas ao fenômeno da variação e da concepção de língua relacionados ao ensino/aprendizagem de língua materna. 
Pudemos perceber que as mudanças oriundas do Estruturalismo, apesar de valorizarem todos os sistemas linguísticos, acabaram por suscitar uma visão de língua baseada na homogeneidade linguística e na preponderância dos enfoques gramaticais em detrimento dos aspectos sociais da linguagem.

Isso trouxe várias consequências para as práticas docentes em salas de aula, as quais, em geral, contribuíram (e, infelizmente, ainda contribuem) para uma discriminação linguística e, consequentemente, para um alto índice de reprovação e evasão escolar.

Com o advento de novas correntes linguísticas, essas práticas começaram a ser questionadas. A Sociolinguística trouxe consigo a importância de conceber as línguas como heterogêneas, como atividades sociais, e de perceber que a variação é um fenômeno inerente a elas. Portanto, se tudo é variação, não existe "erro" na língua.

Como afirmam Cezario e Votre (2011, p. 152):

Além de contribuir para a descrição e explicação de fenômenos linguísticos, a sociolinguística também fornece subsídios para a área de ensino de línguas. Os sociolinguistas postulam que os dialetos das classes desfavorecidas não são inferiores, insuficientes ou corrompidos. Afirmam que esses dialetos são estruturados com base em regras gramaticais, muitas das quais diferentes das regras do dialeto padrão. Dessa forma, a sociolinguística cria nos (futuros) professores uma visão menos preconceituosa e incentiva-os a valorizar todos os dialetos e a mostrar à criança que o dialeto culto é considerado melhor socialmente, mas que estrutural e funcionalmente não é nem melhor nem pior que o dialeto da comunidade do aluno.

A Sociolinguística busca combater o preconceito linguístico e a incentivar os alunos provenientes das camadas populares a utilizarem um registro mais monitorado nos contextos necessários, sem que, com isso, tenham que abandonar suas práticas linguísticas. Enfatiza que apesar de possuírem valores sociais diferentes, todas as variedades linguísticas são estrutural e funcionalmente analisáveis. Portanto, não há língua ou variedade melhor ou pior. A palavra chave aqui não é "certo" ou "errado" e sim adequação. 
Relacionando as visóes de língua e de variação postuladas por esta corrente teórica, poderíamos buscar um ensino de língua materna mais acessível às camadas populares, em que os alunos seriam entendidos como sujeitos históricos, políticos e ideológicos, que se posicionam, mesmo que inconscientemente, frente às situaçôes cotidianas.

A escola, consciente de seu papel, buscaria contribuir na formação de sujeitos críticos e auxiliaria no combate de toda forma de discriminação e preconceito, pois:

Se queremos construir uma sociedade tolerante, que valorize a diversidade, uma sociedade em que as diferenças de sexo, de cor de pele, de opção religiosa, de idade, de condiçóes físicas, de orientação sexual não sejam usadas como fator de discriminação e de perseguição, temos que exigir também que as diferenças nos comportamentos linguísticos sejam respeitadas e valorizadas (BAGNO, 2007, p. 159).

Assim como na língua, para haver uma mudança efetiva, é necessário que haja variação e que uma variante prepondere sobre as outras, para que uma nova visão de ensino/aprendizagem de língua materna seja instaurada, é necessário que as práticas docentes se desvinculem, de fato, das abordagens tradicionais. É verdade que algumas atitudes já estão em transformação. Mas, para que uma mudança realmente se concretize, ainda há muito o que se fazer.

\section{Referências}

ALKMIM, T. M. Sociolinguística - Parte I. In: MUSSALIN, F; BENTES, A. C. (Org.). Introdução à linguística, vol.1. São Paulo: Cortez, 2001. p. 21-47.

ANTUNES, I. Muito além da gramática: por um ensino de línguas sem pedras no caminho. São Paulo: Parábola, 2012.

. Aula de português: encontro \& interação. São Paulo: Parábola, 2013.

BAGNO, M. A inevitável travessia: da prescrição gramatical à educação linguística. In: BAGNO, M.; STUBBS, M.; GAGNÉ, G. Lingua materna, letramento, variaçâo e ensino. São Paulo: Parábola, 2002. p. 13-84. 
. Nada na língua é por acaso. - Por uma pedagogia da variação linguística. São Paulo: Parábola, 2007.

. O que é uma língua? Imaginário, ciência \& hipóstase... . In: LAGARES, X.; BAGNO, M. (Org.). Politicas da Norma e Conflitos Linguísticos. São Paulo: Parábola, 2011. p. 355-387.

BRASIL/SEF. Parâmetros Curriculares Nacionais: terceiro e quartos ciclos do ensino fundamental. Brasília: MEC/SEF, 1998.

CAMACHO, R. G. Sociolinguística - Parte II. In: MUSSALIN, F; BENTES, A. C. (Org.). Introdução à linguística, vol.1. São Paulo: Cortez, 2001. p. $49-75$.

CEZARIO, M. M.; VOTRE, S. Sociolinguística. In: MARTELOTTA, M. (Org.). Manual de linguistica. São Paulo: Contexto, 2011. p. 141-155.

COAN, M.; FREITAG, R. M. K. Sociolinguística variacionista: pressupostos teórico-metodológicos e propostas de ensino. In: Domínios de Linguagem: Revista Eletrônica de Linguistica, vol. 4, no 2 - 20 semestre 2010 - ISSN 19805799. p. 173-194. Disponível em: http://www.seer.ufu.br/index.php/dominiosdelinguagem. Acesso em: 27/08/12.

COSTA, M. A. Estruturalismo. In: MARTELOTTA, M. (Org.). Manual de linguística. Sáo Paulo: Contexto, 2011. p. 113-126.

FARACO, C. A. O Brasil entre a norma culta e a norma curta. In: LAGARES, X.; BAGNO, M. (Org.). Políticas da Norma e Conflitos Linguísticos. São Paulo: Parábola, 2011. p. 259-275.

GUEDES, Paulo Coimbra. A formação do professor de português: que língua vamos ensinar? São Paulo: Parábola, 2006.

ILARI, R. O Estruturalismo linguístico: alguns caminhos. In: MUSSALIN, F.; BENTES, A. C. (Org.). Introdução à linguistica, vol.3. São Paulo: Cortez, 2011. p. 53-92.

MILROY, J. Ideologias linguísticas e as consequências da padronização... . In: LAGARES, X.; BAGNO, M. (Org.). Politicas da Norma e Conflitos Linguisticos. São Paulo: Parábola, 2011. p. 49- 87.

MONTEAGUDO, H. Variação e norma linguística: subsídios para uma (re) visão... . In: LAGARES, X.; BAGNO, M. (Org.). Politicas da Norma e Conflitos Linguisticos. São Paulo: Parábola, 2011. p. 15-48. 
PERFEITO, A. M. Concepçóes de linguagem e análise linguística: diagnóstico para propostas de intervenção. In: CLAPFL - I Congresso Latino-Americano de Professores de Línguas. Anais do I congresso Latino-Americano de Professores de Língua. Florianópolis: EDUSC, 2007. p. 824-836. Disponível em: http://www. cce.ufsc.br/ clafpl/74_Alba_Maria_Perfeito.pdfAcesso: 04/09/12.

REIS, P. C.; MACHADO, D. P.; BARBOSA, S. C. D. A. A Sociolinguística e o ensino de Língua Materna. In: X Congresso Nacional de Educação EDUCERE: I Seminário Internacional de Representaçóes Sociais, Subjetividade e Educação - SIRSSE. Pontifícia Universidade Católica do Paraná - Curitiba, 7 a 10 de dezembro de 2011. p. 6440 - 6450.

SILVA, M. L. A Linguística e a Sociolinguística numa perspectiva brasileira. In: Revista Filosofia Capital. Vol. 4, Edição 8, Ano 2009. ISSN: 1982-6613. Brasília-DF. p. 23-39.

SOARES, M. Linguagem e Escola: Uma perspectiva social. São Paulo: Ática, 1987.

\section{SOCIOLINGÜÍSTICA EN EL AULA: RELACIONES CON LA ENSENÃNZA/APRENDIZAJE DE LENGUA MATERNA}

\section{RESUMEN}

La Sociolingüística trajo consigo la importancia de concebir las lenguas como heterogéneas, como actividades sociales, y de percibir que la variación es un fenómeno inherente a ellas. Con eso, nuevas concepciones teóricas y metodológicas relacionadas al proceso de enseñanzaaprendizaje de lengua materna surgieron. En este artículo, vamos a reflexionar sobre cómo esta corriente teórica puede influir en las prácticas docentes.

PALABRAS-CLAVE: sociolingüística; lengua materna; enseñanza-aprendizaje.

Recebido em: 31/03/2015

Aprovado em: 26/09/2015 